\title{
Differential Interspecific Adaptation to Abiotic Stress by Plantago Species
}

\author{
António Teixeira ${ }^{1,2 \star \dagger}$, Peter E. Toorop ${ }^{1}$ and Pietro P. M. lannetta ${ }^{3}$ \\ ${ }^{1}$ Department of Comparative Plant and Fungal Biology, Royal Botanic Gardens, Kew, Richmond, United Kingdom, \\ ${ }^{2}$ Department of Earth and Environmental Sciences, University of Pavia, Pavia, Italy, ${ }^{3}$ Ecological Sciences, The James Hutton \\ Institute, Dundee, United Kingdom
}

\section{OPEN ACCESS}

Edited by:

Boris Rewald,

University of Natural Resources and Life Sciences, Vienna, Austria

Reviewed by:

Péter Török

University of Debrecen, Hungary

Rubén Retuerto,

University of Santiago

de Compostela, Spain

${ }^{*}$ Correspondence: António Teixeira

antonio.teixeira@bio.uminho.pt

tPresent address: António Teixeira,

Centre of Molecular and Environmental Biology (CBMA), University of Minho, Braga, Portugal

Specialty section:

This article was submitted to Functional Plant Ecology,

a section of the journal

Frontiers in Plant Science

Received: 18 June 2020

Accepted: 05 October 2020

Published: 05 November 2020

Citation:

Teixeira A, Toorop PE and lannetta PPM (2020) Differential Interspecific Adaptation to Abiotic

Stress by Plantago Species.

Front. Plant Sci. 11:573039.

doi: 10.3389/fp/s.2020.573039
The success of seed-based conservation and restoration efforts using native plant species is largely determined by ensuring two key life history transitions are accommodated. These are from "seed to germinated seed" and "germinated seed to established seedling." In turn, optimization of these life history transitions is determined by a "genetic $x$ environmental" interaction and later largely characterized by localized climatic (abiotic) conditions. It is these environmental stress factors that can act as natural selection agents for specific plant-trait combinations, or phenotypes. In turn, such adaptation may also limit a species range. To test the relationship between these two early plant life history stage transitions, "seed to germinated seed" and "germinated seed to established seedling," the attributes were characterized for two species of Plantago that occupy contrasting environments and since these species have potential for native seed-based habit restoration and conservation. The species were Plantago coronopus (L.), localized at lower and drier altitudes, and Plantago lanceolata (L.), characterized as occupying higher and wetter altitudinal clines. Seeds were collected from 20 accessions of six natural populations spanning four European countries for both $P$. lanceolata and $P$. coronopus. Seed germination $(G)$ and seedling establishment $(S)$ data were determined at six temperatures $(T)$ and six water potentials $(\Psi)$, and the data obtained were analyzed using a generalized linear model (GLM). The results indicate that $P$. coronopus has adapted physiologically to its high-altitude conditions such that seed germination and seedling establishment may be more readily achieved in this cooler environment where water is less limiting. In contrast, the lower $\theta_{T}$ of $P$. lanceolata better facilitates more efficient seed germination and seedling establishment in drier and warmer clines of lower altitude. In addition to establishing a genotypic (species) underpin for seed and seedling trait differences observed, the insights gained may also be exploited to best deploy each species in situ for seed-based conservation and restoration efforts.

Keywords: Plantago, seed germination, seedling establishment, abiotic stress, conservation

\section{INTRODUCTION}

Land abandonment is one of the major threats to the Mediterranean biodiversity (Myers et al., 2000) and is mainly the result of socioeconomic changes where less productive areas, which are also less accessible due to steep topography and/or poor road conditions, have been particularly badly affected (Loumou and Giourga, 2003; Rühl et al., 2005). In addition, crop monocultures 
and the intensive use of agrochemicals, which characterize conventional food production systems, leave soils degraded and often bare soils (e.g., olive groves and vineyards) throughout the year, leading to erosive processes and loss of soil nutrients. In semiarid zones where majority of the Mediterranean agro ecosystems are located, restorative agronomic approaches using cover crops (Dazy et al., 2008) would help improve soil function (Dölle and Schmidt, 2009; Moreno-de Las Heras et al., 2009) and help realize a more sustainable system for the long-term (Hobbs and Norton, 1996). One restorative agriculture approach for mainly perennial cropping systems is the reestablishment of wild native or indigenous species using seed-based methodologies. However, the success of deploying wild seed in such restorative efforts demands detailed species- and even ecotype-specific knowledge of seed and seedling traits and their response to local environmental factors (Hernández and Pastor, 2008).

Ambient temperatures and water availability are major factors influencing seed germination and seedling establishment (FinchSavage and Phelps, 1993; Xu et al., 2014; Cochrane et al., 2015; Dürr et al., 2015; Teixeira et al., 2020). Concerning the former, thermal time models of germination rates in response to temperature may be used to estimate "cardinal temperatures," which define temperature minima or "base temperature" $\left(T_{b}\right)$, below which seeds will not germinate (Garcia-Huidobro et al., 1982; Gummerson, 1986; Dahal and Bradford, 1994; Hardegree and Van Vactor, 1999). The cardinal temperature approach also identifies the temperature at which germination is optimal $\left(T_{o}\right)$ and the ceiling temperature when germination is prevented $\left(T_{c}\right)$ (Ellis et al., 1986; Alvarado and Bradford, 2002). The $T_{b}$ is a critical parameter for predictive modeling of the periods during which seed germination is possible (Trudgill et al., 2005), and seeds produced by a community of any given species can show tight regulation of their $T_{b}$ (Garcia-Huidobro et al., 1982; Covell et al., 1986; Dahal et al., 1990; Kebreab and Murdoch, 1999). Thus, cardinal temperatures can relate seed germination data to germination and to seedling development to indicate the potential occurrence of mature plants (Alvarado and Bradford, 2002) and fulfillment of ecological niche (that is, the match of a phenotype to specific environmental conditions; c.f., Arnaud, 2015).

Regarding water availability, changes in soil water content affect soil water potential and so may affect water transport to, and germination of, seeds (Guillemin et al., 2013; Teixeira et al., 2020). The base water potential $\left(\Psi_{b}\right)$ is a critical parameter for use in hydrotime models to predict the germination periods of different species (or ecotypes) in a variety of environmental conditions (Bradford, 1990; Welbaum et al., 1990; Guillemin et al., 2013; Dürr et al., 2015).

In a study conducted to estimate $T_{b}$ and $\Psi_{b}$ parameters of 14 species, Guillemin et al. (2013) reported that the number of potential "germination days" varied little among the climatic years tested but substantially between species. That is, species coexistence appears afforded based on differential ecological niches. In terms of ecological restoration and especially restoration activities, which focus upon the use of native seeds from a range of local species, germination traits and predictive models are especially important since the success of restoration, and species coexistence, may depend on seed germination and seedling establishment (Bischoff et al., 2006).

The genus Plantago (Plantaginaceae) is thought to be an ancient family (Kuiper and Bos, 1992) and is here reported on two common herbaceous ruderal species that tend toward being perennial types: Plantago coronopus with therophyte life form and Plantago lanceolata with therophyte or hemicryptophyte life form. The two species occur widely and appear to lack a strong habitat preference, are found in altitude ranges of 1,100 and 2,300 $\mathrm{m}$, and have distributions spanning Eurasia and occidental Europe, respectively (Castroviejo, 1986-2015). The rosetteforming species are pioneer species of disturbed bare ground (Kuiper and Bos, 1992). Naturally occurring and persistent in the soil seed bank, Plantago species are used for seed-based landscape restoration (Schröder and Prasse, 2013). Particularly, $P$. lanceolata is frequently used in seed cover crop mixtures (Alvarez-Diaz et al., 2016; González et al., 2017) protecting soil and to control pernicious weed species of farmland, and they are also grazing-tolerant (Lawson et al., 2004). P. coronopus is also widely used on well-drained soils, as it is able to establish well despite the potential reduction in available water compared to other soil types (González et al., 2017).

To test the hypothesis that congeneric species may possess distinct traits as adaptations to abiotic stress, i.e., may occupy different ecological niches, we characterized the seed and seedling traits of 10 accessions for each of the two species that were collected from six regions of four countries. The accessions were localized across an array of different altitudes, latitudes, longitudes, and pedoclimatic environments.

\section{MATERIALS AND METHODS}

\section{Plant Material}

Seeds from two species $P$. coronopus and $P$. lanceolata were collected from 50 to 200 plants per accession in 2015, totaling 20 accessions in six regions covering four countries: Canary islands (Ci, Spain), Andalucía (An, Spain), Minho and Trás-os-Montes (PT, Portugal), Asturias (As, Spain), Sussex (Eg, United Kingdom), and Provence-Alpes-Côte d'Azur (Fr, France). The accessions were sampled at the time of natural seed dispersal (late-summer, Supplementary Table S1). Upon collection, seed of all accessions were cleaned and kept in a controlled environment $\left[15^{\circ} \mathrm{C}, 15 \%\right.$ relative humidity $\left.(\mathrm{RH})\right]$ until germination experiments were performed.

\section{Climatic Conditions}

For each accession, we obtained the climatological conditions by cross-referencing their geographic localities with the WORLDCLIM database (Hijmans et al., 2005) using DIVAGIS software (Hijmans et al., 2004). With the obtained interpolated climatological data, we calculated the average annual temperature (AT) plus the maximum $\left(\mathrm{T}_{\max }\right)$ and minimum $\left(\mathrm{T}_{\min }\right)$ temperatures. We also recorded average annual precipitation (AP), the monthly average from November to April [or "winter precipitation" (WP)] and May to October [or "summer precipitation" (SP)], and the sum of the annual 
precipitation ( $\mathrm{AP}_{\text {sum }}$; Supplementary Table $\left.\mathrm{S1}\right)$. A map of the collecting sites was made using The Environmental Stratification of Europe dataset (QGIS Version 2.10.1; Metzger, 2018) with QGIS software version 2.10 (Open Source Geospatial Foundation Project) (Supplementary Figure S1).

\section{Seed Mass}

The seed mass of each accession was recorded as the mean of 96 seeds selected randomly and weighed individually with a precision balance (UMT2 $d=0.1 \mu \mathrm{g}$, METTLER TOLEDO, Leicester, United Kingdom).

\section{Germination and Seedling Development}

Laboratory germination $(G)$ experiments were performed in temperature-controlled incubators (LMS, Sevenoaks, United Kingdom). Seeds were sown on 9-cm-diameter Petri dishes on two layers of filter paper (Whatman ${ }^{\circledR}$ Grade1, Sigma Aldrich, Gillingham, United Kingdom) and saturated with $3.5 \mathrm{ml}$ of sterile Milli- ${ }^{\circledR}$ water (Merck Millipore, Watford, United Kingdom) and placed in closed plastic bags to prevent evaporation. Each replicate comprised a single Petri dish containing 50 seeds, and three replicate experiments were performed independently. Germination temperature regimes ranged from 5 to $30^{\circ} \mathrm{C}$ at $5^{\circ} \mathrm{C}$ intervals at a constant temperature and a 12-h light/12-h dark photoperiod. Germination was scored twice daily for 5 weeks, and germinated seeds were distinguished by protruded radicles ( $>1 \mathrm{~mm}$ ). Germinated seeds were monitored every 3 days to score the date of cotyledon opening and were considered seedlings when the developing shoot meristem was visible and any abnormality was absent (NS). At the end of the test period, seeds that had failed to germinate were cut open and classified by appearance as viable or dead depending of embryo presence/absence (Teixeira et al., 2020).

Germination percentages were calculated, and statistical analyses were undertaken using only viable seed (i.e., total germinated plus ungerminated living seed).

The capacity of the seed to germinate under simulated conditions of water deficit was assessed using polyethylene glycol (PEG) solutions of varying concentrations as osmoticum. These tests were performed in three independent replicate experiments using $3.5 \mathrm{ml}$ of PEG solution ranging from 0 to $-1.0 \mathrm{MPa}$ with 0.2-MPa intervals. Seeds were incubated at constant temperature in filter paper-containing Petri dishes (as described above) and at a constant temperature of $15^{\circ} \mathrm{C}$. Each solution was prepared in triplicate according to Equation (5) described in Hardegree and Emmerich (1990), Equ. 1 (0.129 [PEG] $]^{2} \mathrm{~T}-14.0$ [PEG $^{2}-0.40$ [PEG]). Where "T" is the temperature for germination and "PEG" is MW 8,000 (Sigma Aldrich, Gillingham, United Kingdom). The Petri dishes were placed in closed plastic bags; one dish per treatment per experiment. Each Petri dish containing 50 seeds sown was scored daily, and seeds with protruded radicles $>1 \mathrm{~mm}$ were considered to have completed germination. In order to keep the osmotic solutions at the designated water potential, the germinated seeds were carefully transferred to germination paper in transparent resealable plastic boxes $(17 \mathrm{~cm} \times 12 \mathrm{~cm} \times 5 \mathrm{~cm})$, which was moistened with $15 \mathrm{ml}$ of the same osmotic solution. The boxes were also placed inside sealable plastic bags. The growing seedlings $(S)$ were observed every 3 days to score cotyledon opening. As before, and at the end of the test, nongerminated seeds were cut open and classified by appearance as viable or dead depending on embryo presence/absence, germination percentages were calculated, and further statistical analyses (see below) were undertaken only with viable seeds (germinated plus remaining viable).

\section{Statistical Analysis}

Statistical tests were performed using R v3.6.2 (R Core Team, 2016). The medians and quartiles of the boxplots were calculated using the R-Basic functions. "Germination rate" $\left(\mathrm{GR}_{\mathrm{T}}\right.$ in response to differing temperatures and $\mathrm{GR}_{W}$ for different osmotica) was inferred from the reciprocal of the time to $50 \%$ germination ( $\mathrm{t} 50$ ), which was estimated via a sigmoidal curve fit of the cumulative germination for each dish using the Boltzmann equation (Supplementary Figure S2a). Using the range of constant temperatures of each replicate experiment per accession, they were regressed with a linear model to estimate the "base temperature" at which the germination rate was equal to zero $\left(T_{b} \mathrm{G}\right)$, and "thermal time" $\left(\theta_{T} \mathrm{G}\right)$ was estimated with the reciprocal of the (temperature $\times 1 / t 50$ ) slope value (Supplementary Figure S2b). The "seedling rate" (SR) was inferred from the reciprocal of the time until 50\% of the germinated seeds had open cotyledons (at the constant temperature). The same procedure was used to estimate the base temperature $\left(T_{b}\right)$, at which the rate of development to the seedling stage (for temperature and osmoticum, $\mathrm{SR}_{T}$ and $\mathrm{SR}_{W}$, respectively) was equal to zero ( $T_{b} \mathrm{G}$ and $\mathrm{T}_{b} \mathrm{~S}$, respectively). The thermal time for this transition $\left(\theta_{T} S\right)$ was also estimated as already described above. To estimate the base water potential $\left(\Psi_{b}\right)$ at which the GR was equal to zero and the "hydrotime" $\left(\theta_{H}\right.$; time for transition to seedling stage), a similar procedure to that described above was applied using a range of water potentials (i.e., osmotica) to give estimates of $\theta_{H} \mathrm{G}$ and $\theta_{H} S$, respectively (Supplementary Figures S2c,d). To estimate the temperatures and osmotica at which the germination and development to the seedling stage percentages were the highest, data were fitted with quadratic polynomial equations using the Origin software (OriginLab, Northampton, MA, United States). This identified the optimum temperatures for germination $\left(T_{o} \mathrm{G}\right)$ and for seedlings occurrence $\left(T_{o} S\right)$.

The GLM tests for maximum germination and development to the seedling stage were performed using a binomial distribution with logit link function, with species as predictor factor using the maximum likelihood estimation method, Wald Chi-Square statistics, and contrast pairwise species. The GLM tests of the base temperatures, thermal and hydrotime, optimum temperatures, and base water potential were performed using the above method with a normal distribution and the identity link function after normality and homogeneity of the variances checking using the Shapiro-Wilk and Levene tests, respectively. All GLM tests were performed with the SPSS Statistics for Windows software (Version 21.0). Germination rates and normal seedling development rates were tested using the Kruskal-Wallis test, comparing temperature conditions and osmoticum using the SPSS Statistics for Windows software (Version 21.0). The base 
temperatures and thermal time for germination $\left(T_{b} \mathrm{G}\right.$ and $\theta_{T} \mathrm{G}$, respectively) were regressed against the base temperatures and thermal times for normal seedling development $\left(T_{b} S\right.$ and $\theta_{T} S$, respectively), the base water potentials and hydrotime for germination ( $\Psi_{b} \mathrm{G}$ and $\theta_{H} \mathrm{G}$, respectively) were regressed against the base water potential and hydrotime for normal seedling development ( $\Psi_{b} S$ and $\theta_{H} \mathrm{G}$, respectively), using linear regression with the mean values of the three replicates for each accession and species using the $\mathrm{R}$ basic functions. Base temperatures and water potentials were regressed against thermal and hydrotime, and the $T_{b} \mathrm{G}, T_{b} \mathrm{~S}, \Psi_{b} \mathrm{G}$, and $\Psi_{b} \mathrm{~S}$ were regressed against the climate traits $\mathrm{T}_{\min }, \mathrm{T}_{\max }, \mathrm{WP}$, and $\mathrm{SP}$. The two-way ANOVA tests comparing species' $T_{b} \mathrm{G}$ with $T_{b} \mathrm{~S}$ and $\Psi_{b} G$ with $\Psi_{b} S$ were performed using the SPSS Statistics for Windows software (Version 21.0). The factor analysis of mixed data (FAMD) was performed using the mean values of the three replicates in each physiological trait and the above-described data for geographical and climate conditions as numerical variables with species and region as categorical variables. All numerical variables were centered and scaled to homogenize high discrepancies. The FAMD was performed using the R FactoMineR package (version 2.0). The Spearman's rank correlation was performed for individual selected species with the means of the three replicates of all treatments. The double correlation matrix of Spearman's rank and $p$-values was produced with the $\mathrm{R}$ package corrplot (version 0.84 ) using the correlation matrix (adjusted for ties) and the exact probabilities values previously calculated with the GenStat software (VSN International, Hemel Hempstead, United Kingdom).

Graph theory, a mathematical object corresponding to a network that recently gained much attention, was used to analyze ecological attributes such as biological interaction webs, geneprotein interrelations, and flower and pollinator interactions (Proulx et al., 2005). The approach considers a set of units, called nodes or vertex, connected by edges where nodes represent a component of the network and edges indicate a relationship between them (Windram and Denby, 2015). The graph network analysis of traits was performed with the significant Spearman's rank $p$-values in order to obtain a network graph of physiologic and environmental traits using the significant rho traits, where the significant $p$ values in the graph correspond to the edges and the traits correspond to the nodes in an adjacency matrix. The rho $p$ values of geographical vs. geographical traits and geographical vs. climate traits were excluded from the analysis. The weighted and undirected graph was generated with the $\mathrm{R}$ package igraph (version 1.0.1).

\section{RESULTS}

\section{Temperature Response}

Significant differences were observed in the trait parameters between the two species (Table 1). P. coronopus reached an observed germination median of $88 \%$ at a temperature of $10^{\circ} \mathrm{C}$, the experimental temperature closest to the $T_{o} \mathrm{G}$ of $11.5^{\circ} \mathrm{C}$, while P. lanceolata reached an observed germination median of $51 \%$ at a temperature of $15^{\circ} \mathrm{C}$, the experimental temperature closest to the $T_{o} \mathrm{G}$ of $14.4^{\circ} \mathrm{C}$ (Figure $\mathbf{1 A}$ and Supplementary Table S3). Across geographical regions, $P$. coronopus showed similar germination responses to temperature, except the accession from Ci (Supplementary Figure S4f) that showed high germination from 5 to $25^{\circ} \mathrm{C}$ and from As that showed high germination from 10 to $20^{\circ} \mathrm{C}$ (Supplementary Figure S4e). P. lanceolata also followed similar temperature responses in most regions, except Eg, which showed the lowest germination across temperatures (Supplementary Figure S5d).

Normal seedlings showed significant differences between species (Table 1) with a high response to a broad range

TABLE 1 | Statistical results for the generalized linear model (GLM) tests of the maximum germination (G) and development to the seedling (cotyledon-open) (S) stage performed with the binomial distribution and logit link function with species as a predictor factor using the maximum likelihood estimation method, Wald Chi-Square statistics, and contrast pairwise species.

\begin{tabular}{|c|c|c|c|c|}
\hline Species & & Traits & $P$-values & Wald Chi-Square \\
\hline \multirow[t]{14}{*}{ P. coronopus $x$ P. lanceolata } & Temperature & Germination (\%) & 0.007 & 1.928 \\
\hline & & $T_{b} \mathrm{G}\left({ }^{\circ} \mathrm{C}\right)$ & 0.008 & 7.109 \\
\hline & & $\theta_{T} \mathrm{G}\left({ }^{\circ} \mathrm{C} \mathrm{h}\right)$ & 0.339 & 0.913 \\
\hline & & $T_{0} \mathrm{G}\left({ }^{\circ} \mathrm{C}\right)$ & 0.000 & 16.47 \\
\hline & & Normal seedling development (\%) & 0.007 & 2,157 \\
\hline & & $T_{b} \mathrm{~S}\left({ }^{\circ} \mathrm{C}\right)$ & 0.001 & 11.52 \\
\hline & & $\theta_{T} \mathrm{~S}\left({ }^{\circ} \mathrm{C} \mathrm{h}\right)$ & 0.000 & 23.997 \\
\hline & & $T_{O} \mathrm{~S}\left({ }^{\circ} \mathrm{C}\right)$ & 0.000 & 23.334 \\
\hline & Osmoticum & Germination (\%) & 0.000 & 61.7 \\
\hline & & $\Psi_{b} \mathrm{G}(\mathrm{MPa})$ & 0.120 & 2.417 \\
\hline & & $\theta_{H} \mathrm{G}(\mathrm{MPa}$ h) & 0.002 & 9.799 \\
\hline & & Normal seedling development (\%) & 0.000 & 387.46 \\
\hline & & $\Psi_{b} \mathrm{~S}(\mathrm{MPa})$ & 0.037 & 4.328 \\
\hline & & $\theta_{H} \mathrm{~S}(\mathrm{MPa}$ h) & 0.000 & 65.704 \\
\hline
\end{tabular}

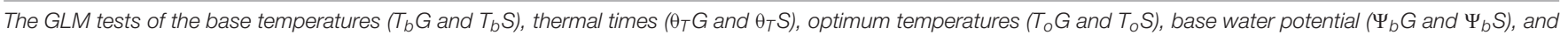

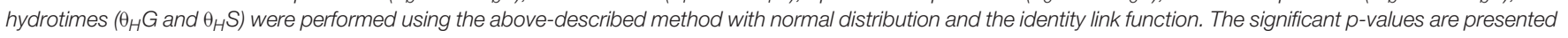
in bold. The overall test results show the Wald Chi-Square test, the degrees of freedom (df) with significant $p$-values in bold, at $\alpha=0$ or $<0.05$ for each condition. 

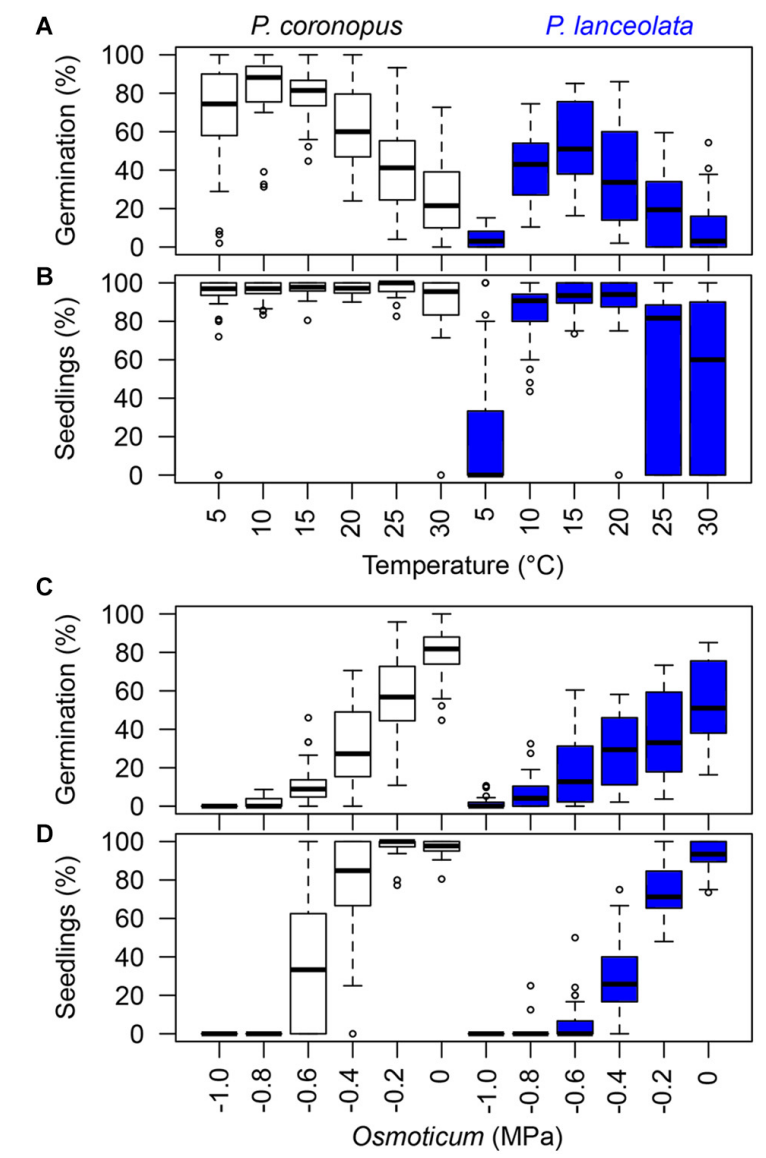

FIGURE 1 | Seed germination percentages calculated from the total viable sowed seeds and normal seedlings as percentage of all germinated seeds, expressing the relative conversion from seed germination to normal seedlings. The boxplots show the minimum, first quartile, median, third quartile, maximum, and the suspected outliers for the germination and seedlings in temperature conditions (A,B) and germination and normal seedlings in osmoticum (C,D). The boxplot colors represent the different species with 10 accessions each: P. coronopus (white); P. lanceolata (blue).

of temperatures for $P$. coronopus and a narrower range of temperatures with a high normal seedling response for $P$. lanceolata near the optimum germination temperature (Figure $1 B$ and Supplementary Figures S3, S4 and Supplementary Table S3).

\section{Osmotic Stress}

Final germination for each of the species showed a gradual decrease of germination with decreasing water potentials (Figure 1C). A mild osmotic stress of $-0.2 \mathrm{MPa}$ moderately decreased the germination in $P$. coronopus and $P$. lanceolata compared with the control $(0.0 \mathrm{MPa})$ by $25 \%$ and $18 \%$, respectively, while a water potential of $-0.8 \mathrm{MPa}$ almost fully reduced germination in both species (Figure 1C and Supplementary Table S4). The development of normal seedlings in osmotic solutions reflects the result for germination of each species (Figure 1D and Supplementary Figures S3, S4 and
Supplementary Table S4), showing significant differences between species (Table 1) with a strong decrease in normal seedling development at $-0.4 \mathrm{MPa}$ in $P$. coronopus when compared with the control. Across geographical regions, the inhibition by osmotic stress on normal seedling development was particularly evident in all $P$. lanceolata accessions (Supplementary Figure S4).

\section{Germination and Normal Seedling Development Rates}

Germination rates and seedling development rates $\left(\mathrm{GR}_{\mathrm{T}}\right.$, $\mathrm{SR}_{\mathrm{T}}$ ) differed between temperatures and osmoticum treatments $\left(\mathrm{GR}_{\mathrm{W}}, \mathrm{SR}_{\mathrm{W}}\right)$. Contrary to $P$. coronopus where the $\mathrm{GR}_{\mathrm{T}}$ and $\mathrm{SR}_{\mathrm{T}}$ increased steadily from 5 to $30^{\circ} \mathrm{C}$ (Supplementary Figures S5a,b), P. lanceolata showed a transient increase in $\mathrm{GR}_{\mathrm{T}}$, with the fastest germination and seedling development at $20^{\circ} \mathrm{C}$. Moderate osmotic stress only slightly decreased $P$. coronopus $\mathrm{GR}_{\mathrm{W}}$, but a strong drop was observed at $-0.8 \mathrm{MPa}$. Normal seedling development rates in osmoticum $\left(\mathrm{SR}_{\mathrm{W}}\right)$ were generally lower than $\mathrm{GR}_{\mathrm{W}}$, reaching an $\mathrm{SR}_{\mathrm{W}}$ of zero at $-0.8 \mathrm{MPa}$ for both species (Supplementary Figure S5d).

\section{Base Temperatures, Thermal Times, Base Water Potentials, and Hydrotimes}

The germination base temperatures $\left(T_{b} \mathrm{G}\right)$ showed a small difference for the two species, $(P=0.008)$ (Table 1) with values of $2.0^{\circ} \mathrm{C}$ for $P$. coronopus and $3.0^{\circ} \mathrm{C}$ for $P$. lanceolata (Supplementary Table S2). Similarly, base temperatures for normal seedling development $\left(T_{b} S\right)$ also differed $(P=0.001)$ (Table 1). $P$. coronopus showed a lower $T_{b} \mathrm{~S}\left(1.7^{\circ} \mathrm{C}\right)$ when compared with the $T_{b} \mathrm{G}(P=0.005)$ where $P$. lanceolata showed similar values (Figure 2A and Supplementary Table S2). Despite this, positive correlations were found for both species between the $T_{b} \mathrm{G}$ and the $T_{b} \mathrm{~S}$ ( $r h o=0.564, P=0.022$; rho $=0.745$, $P=0.004$ ) (Figure 2E). The base water potential for normal seedling development $\left(\Psi_{b} S\right)$ differed between species $(P=0.037)$, in contrast with the base water potential for germination $\left(\Psi_{b} \mathrm{G}\right)$ (Table 1). $P$. coronopus and $P$. lanceolata showed a $\Psi_{b} S$ that was higher than the $\Psi_{b} \mathrm{G}(P=0.0001)$ (Figure 2B) with values of -0.8 and $-1.0 \mathrm{MPa}$ for the former and -0.7 and $-1.1 \mathrm{MPa}$ for the latter species (Supplementary Table S2). Unlike the positive correlations for $T_{b} \mathrm{G}$ and $T_{b} \mathrm{~S}$, both species did not show significant correlations between $\Psi_{b} \mathrm{G}$ and $\Psi_{b} \mathrm{~S}$ (Figure 2F). Differences were found in normal seedling development thermal time $\left(\theta_{T} S\right)$ between the species but not for germination thermal time $\left(\theta_{T} G\right)$, although strong positive correlations were observed between these traits in both species (Figure 2G). Differences were found for both germination hydrotime $\left(\theta_{H} \mathrm{G}\right)$ and normal seedling development hydrotime $\left(\theta_{H} \mathrm{~S}\right)$, but only $P$. coronopus revealed a significant correlation between both traits (Figure $2 \mathbf{H}$ ). Both species showed a higher $\theta_{T}$ and $\theta_{H}$ for normal seedling development than for germination (Figures 2C,D).

\section{Factor Analysis of Mixed Data}

An FAMD for $P$. coronopus and $P$. lanceolata was performed using the recorded physiological, geographical, and 

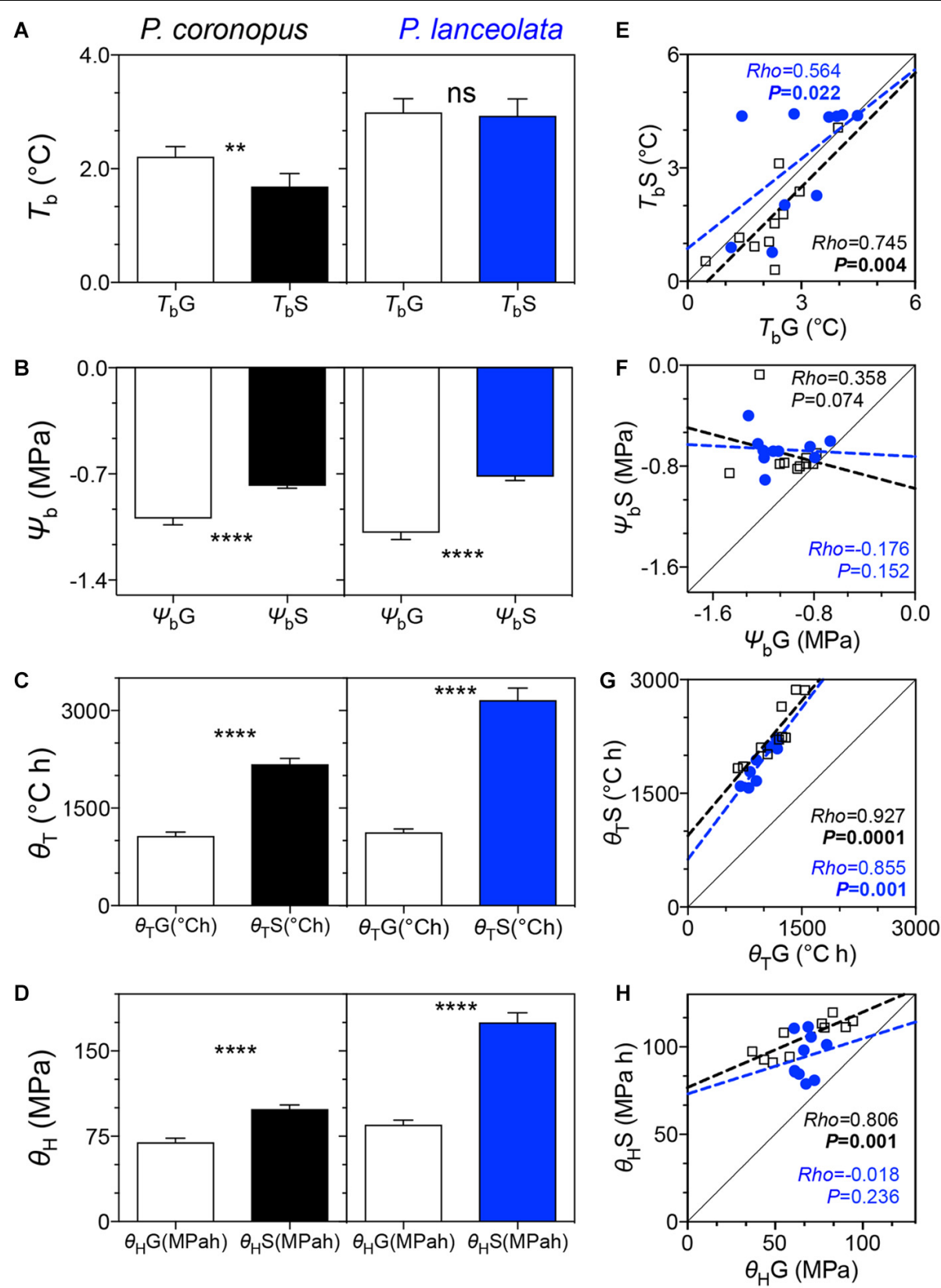

FIGURE 2 | Comparison of base temperature, base water potential, thermal time, hydrotime, and respective linear traits correlations for germination and normal seedling development for 10 accessions of $P$. coronopus (black) and $P$. lanceolata (blue): (A) - germination base temperature ( $T_{b}$ G) and normal seedling development base temperature $\left(T_{b} S\right)$; (B) - germination base water potential $\left(\Psi_{b} G\right)$ and normal seedling development base water potential $\left(\Psi_{b} S\right)$; $(\mathbf{C})$ - germination thermal time $\left(\theta_{T} \mathrm{G}\right)$ and normal seedling development thermal time; (D) - germination hydrotime $\left(\theta_{H} \mathrm{G}\right)$ and normal seedling development hydrotime $\left(\theta_{H} S\right)$. Linear regressions of the base temperatures for germination $\left(T_{b} G\right)$ against the base temperatures for normal seedling development $\left(T_{b} S\right)$ (E), base water potential for germination $\left(\Psi_{b} G\right)$ against the base water potential for normal seedling development $\left(\Psi_{b} S\right)(\mathbf{F})$, germination thermal time $\left(\theta_{T} G\right)$ against the normal seedling development thermal time $\left(\theta_{T} \mathbf{S}\right) \mathbf{( G )}$, and germination hydrotime $\left(\theta_{H} \mathbf{G}\right)$ against the normal seedling development hydrotime $\left(\theta_{H} S\right)$ (H). Histograms indicate mean \pm SEM of two-way ANOVA test comparing the different traits. Asterisks denote the significant difference of $p$-values where: ${ }^{\star \star} p=0.01 ;{ }^{\star \star \star \star} p=0.0001 ;$ ns, non-significant at $\alpha=0.05$. The scatterplot colors represent the mean values of three replicates by species accession.

meteorological traits (Figure 3). The first two dimensions of the FAMD for P. coronopus explained $35.0 \%$ and $22.2 \%$ of the overall variance and for $P$. lanceolata $34.1 \%$ and $26.7 \%$.

The geographical and climate conditions showed a strong contribution to the overall variation for both species (Figures 3A,C). The individual factor maps showed similar and clear clustering by geographical region in both species (Figures 3B,D). In the FAMD for $P$. coronopus, the first dimension showed the association of altitude with the base temperature, thermal time, and hydrotime 


\section{P. coronopus}
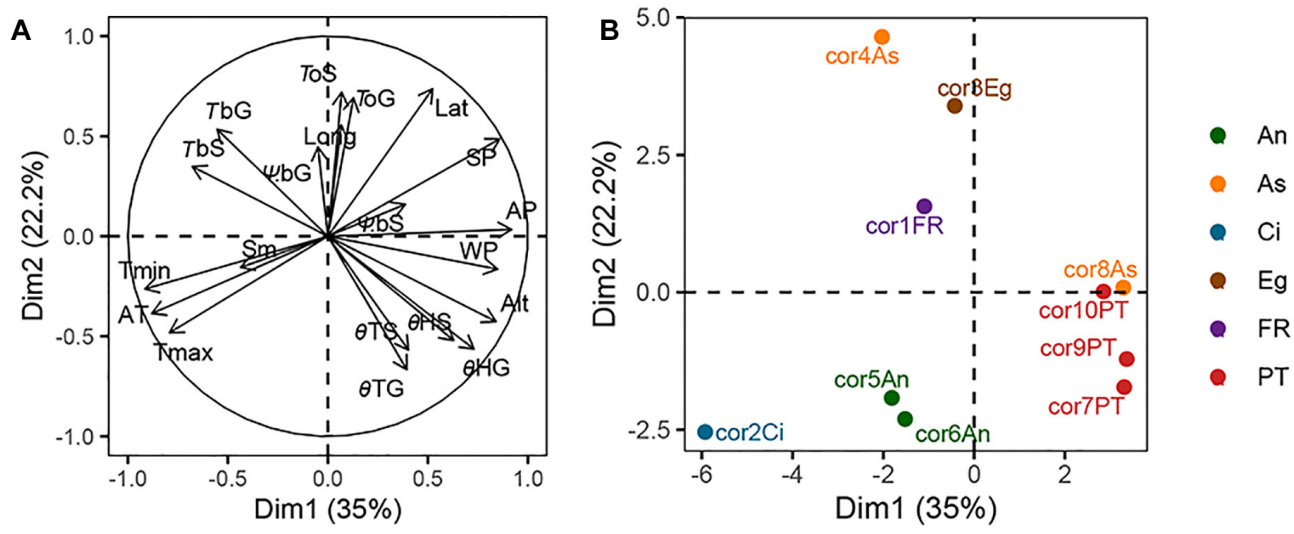

P. lanceolata
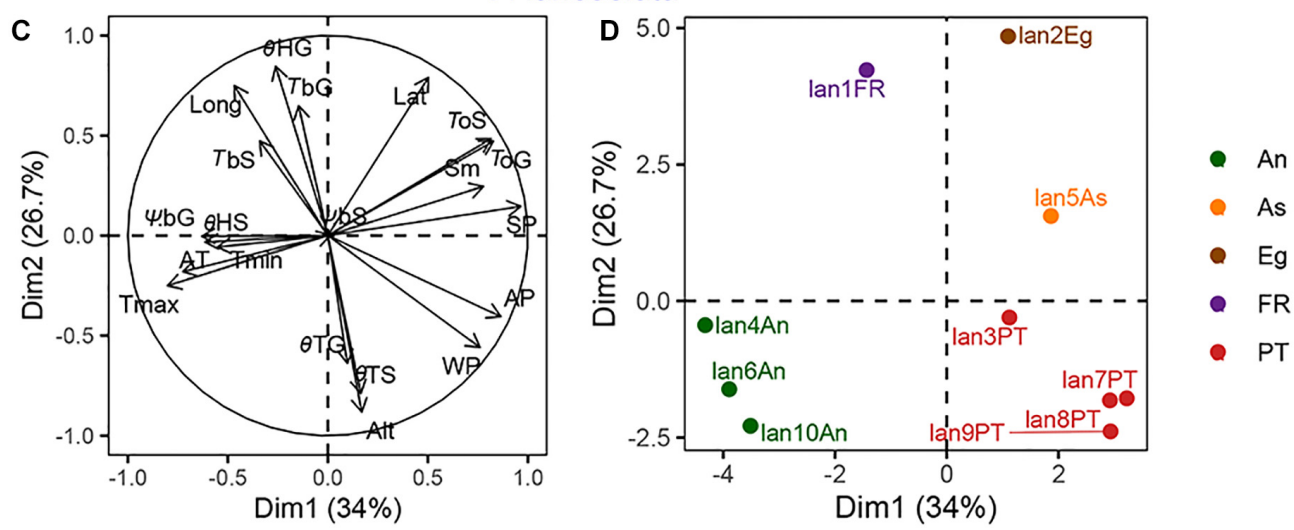

FIGURE 3 | Factor analysis of mixed data (FAMD) analysis with species as categorical variables and physiological traits, provenance climate conditions, and geographical coordinates as continuous variables. (A,C) display the quantitative variables that contribute to the total variance; (B,D) display accessions plotted by color-coded regions for $P$. coronopus and $P$. lanceolata, respectively. Each accession name contains a species code, accession number, and the region acronym. The environmental temperatures ( $T_{\max }, T_{\min }$, and $\left.T_{a}\right)$, environmental precipitation $\left(A_{p}, S_{p}\right.$, and $\left.W_{p}\right)$, geographical coordinates (Alt, Lat, and Long), physiological traits $\left(T_{b} G, T_{b} S, T_{o} G, T_{o} S, \Psi_{b} G, \Psi_{b} S, \theta_{T} G, \theta_{T} S, \theta_{H} G\right.$, and $\left.\theta_{H} S\right)$, and seed mass (Sm).

due its high contribution to the variance, but $T_{b} S$ and $\theta_{H} \mathrm{G}$ revealed a strong correlation (up to 0.73 ) with this dimension. In this species, the second dimension explained the effect of the latitude positively correlated with the optimum temperatures, opposite to $\theta_{T} \mathrm{G}$ that was negatively correlated (Figure 3A). In the FAMD for $P$. lanceolata, the first dimension showed the optimum temperatures and seed mass similarly affected by climate conditions, particularly summer precipitation. The second dimension showed that thermal times, $\theta_{T} \mathrm{G}$ and $\theta_{T} \mathrm{~S}$, were similarly affected by altitude and $T_{b} \mathrm{G}$ and $\theta_{H} \mathrm{G}$ were affected by longitude (Figure 3B).

\section{Correlations of Physiological, Spatial, and Meteorological Traits}

At the collecting sites, the climate conditions vary widely, with only $129 \mathrm{~mm}$ annual precipitation in the Canary Islands to $1,432 \mathrm{~mm}$ in the north of Portugal and $713 \mathrm{~mm}$ in the south of England. The mean annual temperatures range from $20^{\circ} \mathrm{C}$ in the Canary Islands to around $10^{\circ} \mathrm{C}$ in the north of Spain and the south of England (Supplementary Table S1).

The bivariate correlation rank coefficients allowed the evaluation of significant correlations between climate and geographical traits with physiological traits for $P$. coronopus and $P$. lanceolata (Figure 4). P. coronopus showed significant correlations of altitude with base temperatures and hydrotime for both germination and normal seedling development, although only base water potential for germination shows the same correlation. This contrasts with $P$. lanceolata where only correlations of altitude with the hydrotime for germination and thermal time for germination and normal seedling development were found. In both species, the optimum temperatures $\left(T_{o} \mathrm{G}\right.$ and $T_{o} S$ ) were correlated with the latitude, while in $P$. coronopus (but not $P$. lanceolata), the latitude was also correlated with the base water potential $\left(\Psi_{b} \mathrm{G}\right.$ and $\left.\Psi_{b} \mathrm{~S}\right)$; in $P$. lanceolata (but not $P$. coronopus), latitude showed correlations with base temperatures $\left(T_{b} \mathrm{G}\right.$ and $\left.T_{b} \mathrm{~S}\right)$ and with thermal time and hydrotime $\left(\theta_{T} \mathrm{G}\right.$ and $\left.\theta_{H} \mathrm{G}\right)$. P. coronopus showed positive correlations of $T_{b} \mathrm{G}$ and $T_{b} \mathrm{~S}$ with environmental temperature 


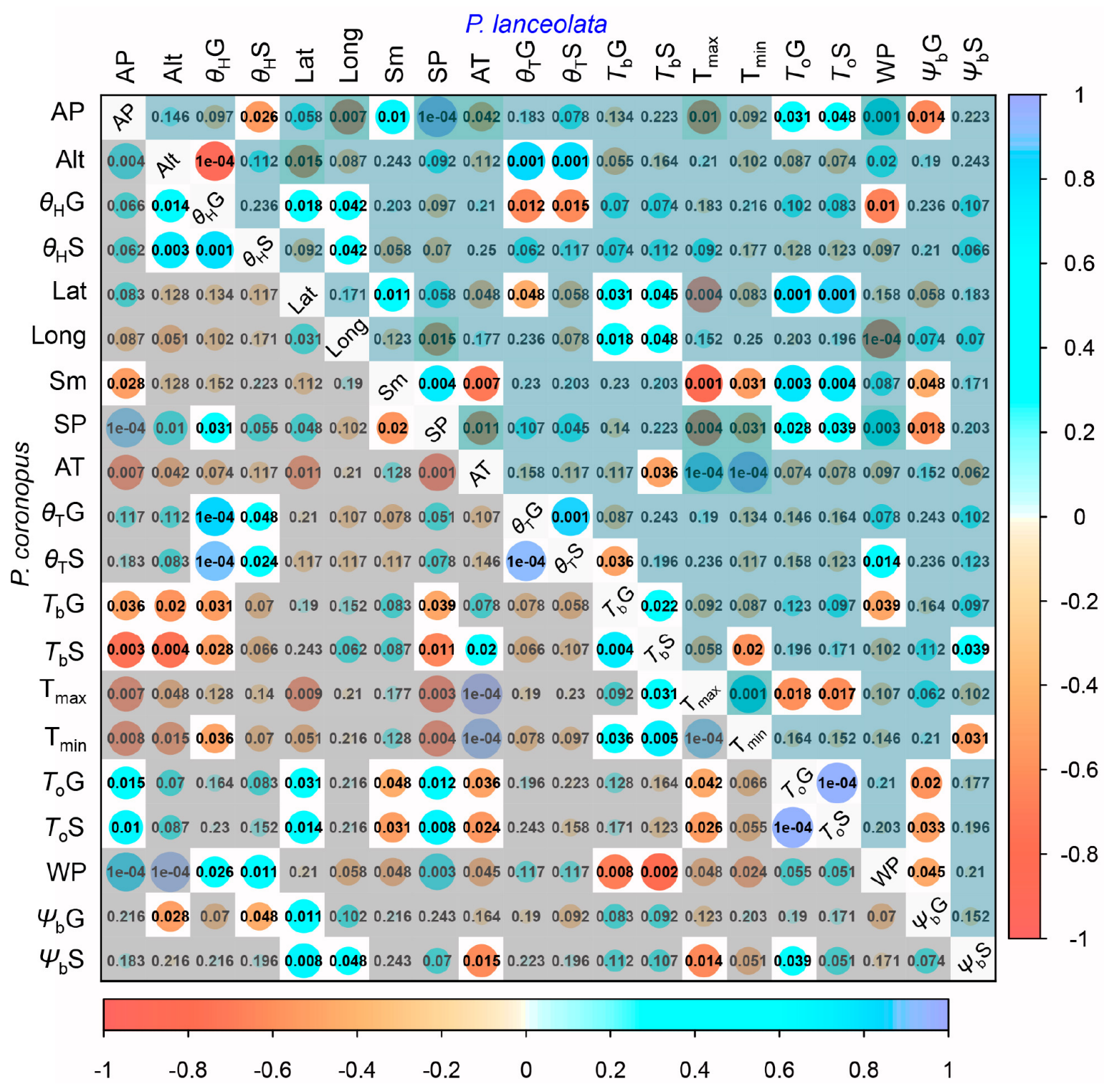

FIGURE 4 | Spearman's correlation rank diagonal matrix of the geographical, climatic, and experimental data variables (Supplementary Tables S1, S2) for $P$. coronopus (lower) and P. lanceolata (upper). Each matrix displays the color-coded correlation coefficients (rho) explained by the lateral and bottom color key. The circle sizes represent the rho values with the exact $p$-values, shaded if $P>0.05$ or if not correlated with physiological traits.

traits, while in $P$. lanceolata, only the $T_{b} \mathrm{~S}$ showed such significant negative correlations. Surprisingly, the $\mathrm{T}_{\min }$ negatively correlated with $P$. coronopus $\theta_{H} \mathrm{G}$ (Figure 4). In both species, $T_{0} \mathrm{G}$ and $T_{o} S$ correlated with environmental precipitation traits, but only $P$. coronopus showed positive correlations between precipitation and hydrotime traits and negative correlations of all three precipitation traits with the base temperatures. $P$. lanceolata showed negative $\theta_{H} \mathrm{G}$ and positive $\theta_{T} S$ correlations with WP. Contrary to $P$. coronopus, the $\Psi_{b} \mathrm{G}$ of $P$. lanceolata was negatively correlated with all precipitation traits (Figures 4, 5G,H). In both species, the $\Psi_{b} \mathrm{~S}$ showed correlations with environmental temperature traits: in P. coronopus with $\mathrm{AT}$ and $\mathrm{T}_{\max }$ and in $P$. lanceolata with $\mathrm{T}_{\min }$ (Figures 4, 5B). The $P$. coronopus seed mass $(\mathrm{Sm})$ was correlated negatively with the environmental precipitation values and with $T_{o} \mathrm{G}$ and $T_{o} S$ (Figure 4). Meanwhile, $P$. lanceolata seed mass was positively correlated with $\mathrm{SP}$ and $\mathrm{AP}$, as well as with $T_{o} \mathrm{G}$ and $T_{o} \mathrm{~S}$. A positive correlation for $P$. lanceolata $\mathrm{Sm}$ was also found with latitude, and negative correlations were found with the environmental temperature conditions (Figure 4). The correlation analysis demonstrated clear differences in the strategies of these two Plantago species to cope with environmental conditions.

\section{Graph Network Analysis}

Plantago coronopus and P. lanceolata differed in the established community modules and the connected nodes within and among 

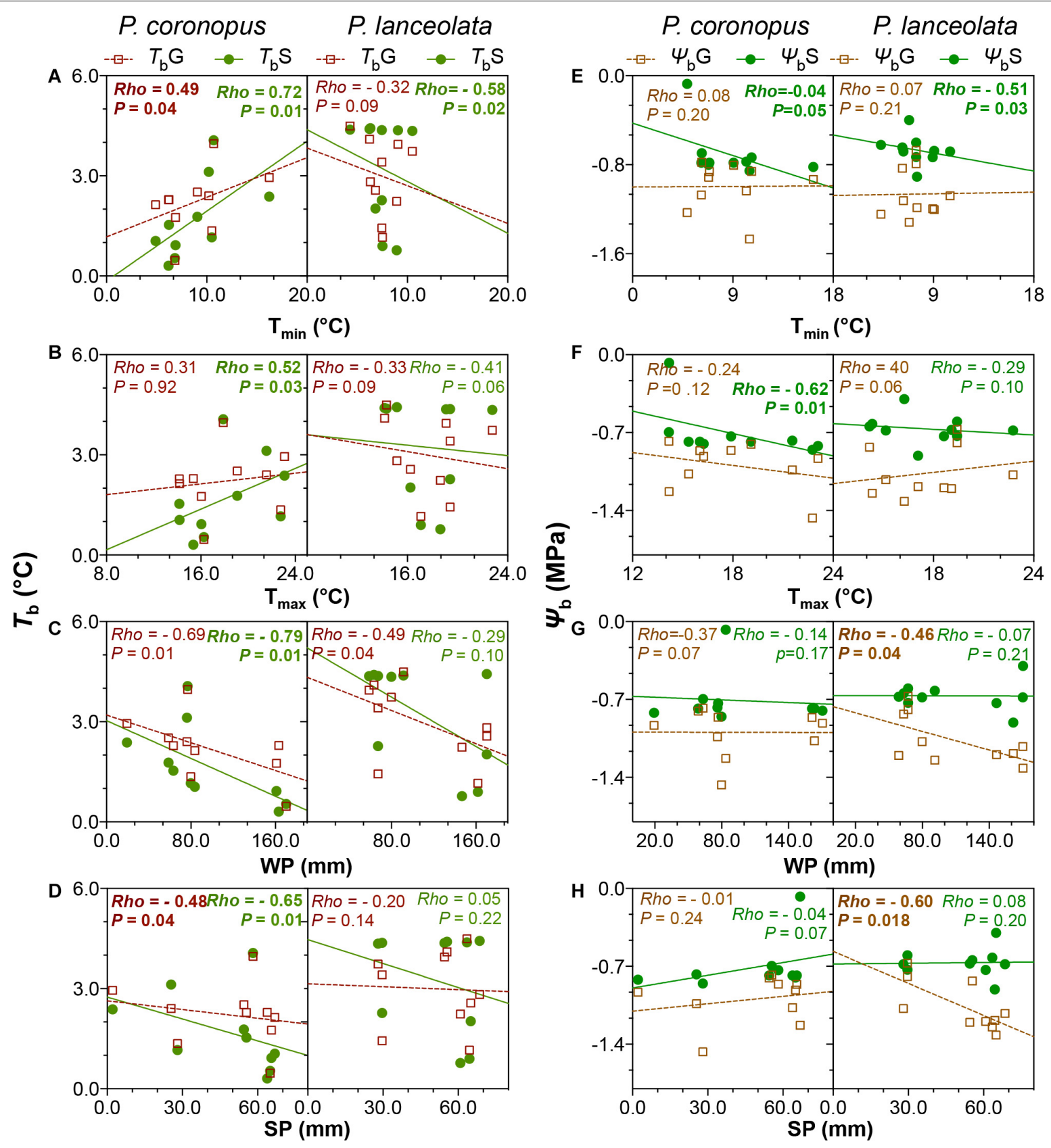

FIGURE $\mathbf{5}$ | Linear regressions for $P$. coronopus and $P$. lanceolata base temperatures (A-D) and base water potentials (E-H) against the climate traits: minimum $\left(T_{\min } ; \mathbf{A}, \mathbf{E}\right)$ and maximum $\left(\mathrm{T}_{\text {max }} ; \mathbf{B}, \mathbf{F}\right)$ temperatures; winter $(\mathrm{WP} ; \mathbf{C}, \mathbf{G})$ and summer $(\mathrm{SP} ; \mathbf{D}, \mathbf{H})$ precipitation. For each species, the means of three replicate values of 10 accessions were plotted. In each panel, $T_{b} G$ is displayed by brown open squares and brown dotted regression lines, and $T_{b} S$ by green closed symbols and green solid regression lines. Osmoticum traits show similar representation. Each panel shows the Spearman's correlation (rho) coefficients and $p$-values.

communities (Figure 6). The network with two P. coronopus community modules highlighted that the base temperature for normal seedling development and the germination hydrotime played a key role due to its higher connectivity degree with other traits. The $\theta_{H} \mathrm{G}$ trait was more affected by precipitation than temperature conditions, whereas $T_{b} S$ was similarly affected by both climacteric traits (Figure 6A). In contrast, $P$. lanceolata showed that the $\theta_{H} \mathrm{G}$ trait connected only with winter precipitation but not summer precipitation (Figure 6B). P. lanceolata was organized in three community modules, highlighting a key role for the seed mass due to its higher connectivity degree with other traits within and between communities. This trait was shown to be strongly affected by temperature and precipitation associated with both optimum temperatures for germination and seedling development, as became clear also in the correlation analysis. Contrary to 

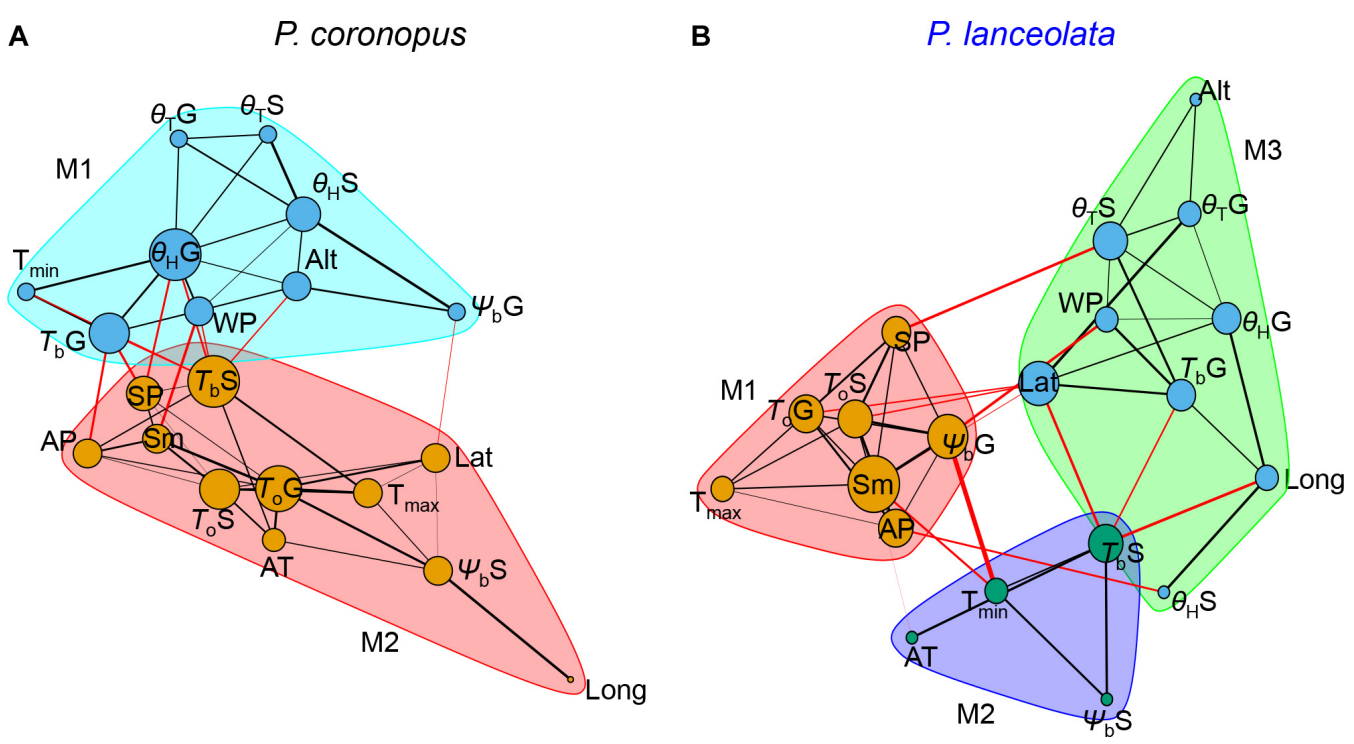

FIGURE 6 | Undirected graph network object of the Spearman's rank correlation $p$-values of $P$. coronopus (A) and $P$. lanceolata (B) species. The nodes (circles) correspond to the variable traits, and the edges (lines) correspond to the significant rho $p$-values of two variables in the correlation matrix. The amount of nodes connected depends on the number of significant $p$-values of one variable with all the other variables. The network graph displays edges that are most likely within (black lines) and among (red lines). Node size corresponds to the degree of connections; edge widths correspond to the logarithm of the edge weight of the $p$-value between the two nodes; module communities (M-shaded) are based on edge betweenness (Newman-Girvan algorithm).

$P$. coronopus, the base temperature for normal seedlings in $P$. lanceolata was associated with both latitude and longitude, and the germination base water potential was mostly associated with the latitude and precipitation values (Figure 6B). These results underline that in these two species, the physiologic traits responded differently to the environmental stimuli.

\section{DISCUSSION}

Our results indicated that the two Plantago species exhibited significantly different ecological strategies with clear differences in all analyzed physiologic traits except for thermal time and base water potential for germination (Table 1). P. coronopus showed a seedling base temperature $\left(T_{b} S\right)$ lower than the germination $\left(T_{b} \mathrm{G}\right)$, and in $P$. lanceolata, the $T_{b} \mathrm{~S}$ was not dissimilar from the $T_{b} \mathrm{G}$, implying that normal seedling development does not present an arrested transition between radicle protrusion and normal seedling development. However, a dissimilar thermal time $\left(\theta_{T}\right)$ was found for the two species, with lower values for $P$. coronopus' $\theta_{T} S$ and $\theta_{T} G$ (Supplementary Table S2), suggesting that $P$. coronopus can germinate and progress seedling development in lower temperature environments than $P$. lanceolata. Despite a similar range, altitude was correlated negatively with $T_{b} \mathrm{G}, T_{b} \mathrm{~S}$, and water base $\left(\Psi_{b} \mathrm{G}\right)$ in $P$. coronopus, but not in $P$. lanceolata, which suggests functional adaptation of the former species to cold environments. This was supported not only by the positive correlation of $T_{b} \mathrm{G}$ and $T_{b} \mathrm{~S}$ with the environmental $\mathrm{T}_{\min }$ and by the very high seed germination and normal seedling development at $5^{\circ} \mathrm{C}$ but also the positive correlation in $P$. lanceolata of thermal times with altitude.
Results for $P$. coronopus contrast with a recent study testing the initial temperature of seed germination $\left(T_{b}\right)$ of 49 species from altitudinal temperate climate, in which Rosbakh and Poschlod (2015) conclude that the $T_{b}$ is strongly negatively correlated with habitat temperature. Results for P. lanceolata were in line, revealing a $\mathrm{T}_{\min }$ negative correlation but only for $T_{b} \mathrm{~S}$ (Figure 5). Apparently, $P$. coronopus displays the capacity for soil emergence before the winter frost at temperature profiles, which match with first autumn precipitations. Though it should be noted that the current study design focuses on intraspecific as opposed to interspecific variations, as such, the geographical/habitat sampling may have an effect on the outcome. Altitude negatively correlated with the $T_{b}$ of $P$. coronopus, and the capacity to enable life history transitions at low ambient temperatures could be also explained by the higher precipitation at higher altitude (Figure 4 and Supplementary Table S1). The northern distribution range of $P$. coronopus was restricted to coastal areas, whereas a frequent inland distribution occurs mainly in southern latitudes (Schat, 1981; Kuiper and Bos, 2012), indicating relatively high frost sensitivity. On the other hand, the species showed a continuous increase of germination rate $\left(\mathrm{GR}_{\mathrm{T}}\right)$ up to $30^{\circ} \mathrm{C}$ (Supplementary Figures S3a,b), indicating also high temperature tolerance. This result agrees with reported values for winter and summer weed species where the germination rate increases from 10 to $30^{\circ} \mathrm{C}$ (Steinmaus et al., 2000). P. coronopus demonstrated a $T_{b}$ that coincides with favorable precipitation events whenever they occur during the "germination" (i.e., sufficiently warm) season, whereas $P$. lanceolata traits seem more suited for germination only in early autumn when the conditions are favorable - avoiding the later season's low temperatures, which was corroborated by the positive correlations of $T_{b}$ with 
the geographical traits and confirmed by the low germination at $5^{\circ} \mathrm{C}$. P. lanceolata fresh seeds revealed a dormancy degree dependent on the ecotype (van Groenendael, 1986), which explains the observed lower germination values at an optimum temperature and reflects unsuitable environmental conditions, when the probability of seedling survival is low. This is in line with reports stating that seedlings, which have sprouted early in the growth season with a consequently longer time for development, have a lower risk of mortality under subsequent adverse environmental factors (Ross and Harper, 1972; Harper and Harper, 1977).

Contrary to the base temperatures, the base water potential for normal seedling development showed a strong increase, suggesting that the normal seedling development is more limited by water deficit than by the temperature stress. Both species showed an expected higher $\theta_{H} \mathrm{~S}$ than $\theta_{H} \mathrm{G}$; however, only $P$. coronopus showed a positive correlation between the hydrotime for germination and normal seedling development where the $\theta_{H} \mathrm{G}$ seems to be a major trait player. The $\theta_{H}$ value quantifies the inherent speed of germination, which can vary among species and physiological states being a constant for all seed fractions. Meanwhile, the $\Psi_{b}$ threshold values vary among seed lots within a species (Bradford, 2002), indicating that $P$. coronopus $\Psi_{b} \mathrm{~S}$ is not the limitation trait in water deficit but the $\Psi_{b} \mathrm{G}$. This is contrary to $P$. lanceolata, where the seedling conversion was lower in osmotic stress. Indeed, $P$. coronopus $\Psi_{b} \mathrm{~S}$ showed a negative correlation with the $\mathrm{T}_{\max }$, indicating higher adaptation of seedlings to osmotic stress in regions with a higher summer temperature, supported by the positive $\Psi_{b} \mathrm{~S}$ correlations with the latitude and by the germination and normal seedling percentages under mild stress. This contrasts with $P$. lanceolata that showed a $\Psi_{b} \mathrm{G}$ preference for higher water availability and $\Psi_{b} S$ for mild temperature environments, as indicated by the negative correlations with these environmental traits. A field study comparing $P$. lanceolata survival in dry and wet site conditions showed that, at dry sites, almost all plants died after a period of drought in the summer of the second year, whereas the wet site had the lowest mortality rate (van Tienderen, 1992). This difference in water stress tolerance for these two species is particularly evident when the conversion from germinated seeds to normal seedlings was observed, with P. coronopus close to $40 \%$, whereas P. lanceolata showed marginal values at $-0.6 \mathrm{MPa}$ (Figure 1D).

It was reported that seed mass is positively associated with germination across a variety of environments (Pearson et al., 2002; Kahmen and Poschlod, 2008). A study in the early eighties in the Netherlands reported a decrease of P. lanceolata seed mass from plants grown in dry sites, with the capacity to germinate reduced with decreasing seed sizes, in contrast to wet sites, where plants produced larger seeds that germinated better at lower temperatures and had a lower optimum temperature (van Groenendael, 1986). In agreement, our results revealed that, for this species, seed mass $(\mathrm{Sm})$ increased with summer precipitation (May-October), when the seed development and ripening occurs, and correlated negatively with environmental temperatures, emphasizing that the species preferred lower temperature environments. The observed positive correlation of Sm with the $T_{o}$ for germination and normal seedling development and the negative correlation with $\Psi_{b} \mathrm{G}$ explain the central position of $P$. lanceolata seed mass in the community module with physiologic traits in the network analysis (Figure 6).

\section{CONCLUSION}

Our results showed clear species-specific minimum temperature and minimum water requirements for germination and seedling development. Geographical and environmental traits highly contributed to seed functional traits, with the base temperature for normal seedling development as the most central trait in $P$. coronopus and the seed mass associated with similar functional traits in $P$. lanceolata. These results reveal diverse ecological strategies with species-specific importance for functional traits.

\section{DATA AVAILABILITY STATEMENT}

All datasets presented in this study are included in the article/Supplementary Material.

\section{AUTHOR CONTRIBUTIONS}

AT, PT, and PI conceptualized the work, analyzed the data, discussed the results, and wrote the manuscript. AT conducted the field sampling and laboratory experiments. All authors contributed to the article and approved the submitted version.

\section{FUNDING}

The research leading to these results has received funding from the People Programme (Marie Curie Actions) of the European Union's Seventh Framework Programme FP7/2007-2013/ under REA Grant Agreement Number 607785. The Royal Botanic Gardens, Kew, receives grant-in-aid from DEFRA. The James Hutton Institute was supported by the Rural and Environment Science and Analytical Services (RESAS), a Division of the Scottish Government.

\section{ACKNOWLEDGMENTS}

We are grateful to Candido Galvez Ramirez (Semillas Silvestres) and Álvaro Bueno (Jardín Botánico Atlántico) for their valuable assistance in choosing the seed collecting sites. We also thank Matías Hernández González, Stephanie Frischie (Semillas Silvestres), and Eduardo Fernaindez Pascual (Royal Botanic Gardens, Kew) for their help in seed collecting.

\section{SUPPLEMENTARY MATERIAL}

The Supplementary Material for this article can be found online at: https://www.frontiersin.org/articles/10.3389/fpls.2020. 573039/full\#supplementary-material 


\section{REFERENCES}

Alvarado, V., and Bradford, K. J. (2002). A hydrothermal time model explains the cardinal temperatures for seed germination. Plant Cell Environ. 25, 1061-1069. doi: 10.1046/j.1365-3040.2002.00894.x

Alvarez-Diaz, J. E., Santa-Regina, M. C., and Santa-Regina, I. (2016). Perturbation experiments in community plant species during recovery from agricultural abandonment in a semi-arid region of Central-Western Spain. J. Environ. Protect. 7:1618. doi: 10.4236/jep.2016.711133

Arnaud, P. (2015). “The ecological niche: history and recent controversies," in Handbook of Evolutionary Thinking in the Sciences, eds T. Heams, H. Philippe, and L. Guillaume (Dordrecht: Springer), 547-586. doi: 10.1007/978-94-0179014-7_26

Bischoff, A., Vonlanthen, B., Steinger, T., and Müller-Schärer, H. (2006). Seed provenance matters-effects on germination of four plant species used for ecological restoration. Basic Appl. Ecol. 7, 347-359. doi: 10.1016/j.baae.2005.07. 009

Bradford, K. J. (1990). A water relations analysis of seed germination rates. Plant Physiol. 94, 840-849. doi: 10.1104/pp.94.2.840

Bradford, K. J. (2002). Applications of hydrothermal time to quantifying and modeling seed germination and dormancy. Weed Sci. 50, 248-260. doi: 10 1614/0043-1745(2002)050[0248:aohttq]2.0.co;2

Castroviejo, S. (1986-2015). Flora Iberica Vol. XVIII PlantaginaceaeScrophulariaceae. Madrid: Real Jardín Botánico CSIC.

Cochrane, J. A., Hoyle, G. L., Yates, C., Wood, J., and Nicotra, A. B. (2015). Climate warming delays and decreases seedling emergence in a Mediterranean ecosystem. Oikos 124, 150-160. doi: 10.1111/oik.01359

Covell, S., Ellis, R. H., Roberts, E. H., and Summerfield, R. J. (1986). The influence of temperature on seed germination rate in grain legumes I. A comparison of chickpea, lentil, soyabean and cowpea at constant temperatures. J. Exper. Bot. 37, 705-715. doi: 10.1093/jxb/37.5.705

Dahal, P., and Bradford, K. J. (1994). Hydrothermal time analysis of tomato seed germination at suboptimal temperature and reduced water potential. Seed Sci. Res. 4, 71-80. doi: 10.1017/S096025850000204X

Dahal, P., Bradford, K. J., and Jones, R. A. (1990). Effects of priming and endosperm integrity on seed germination rates of tomato genotypes I. Germination at suboptimal temperature. J. Exper. Bot. 41, 1431-1439. doi: 10.1093/jxb/41.11. 1431

Dazy, M., Jung, V., Férard, J. F., and Masfaraud, J. F. (2008). Ecological recovery of vegetation on a coke-factory soil: role of plant antioxidant enzymes and possible implications in site restoration. Chemosphere 74, 57-63. doi: 10.1016/j. chemosphere.2008.09.014

Dölle, M., and Schmidt, W. (2009). The relationship between soil seed bank, above-ground vegetation and disturbance intensity on old-field successional permanent plots. Appl. Veget. Sci. 12, 415-428. doi: 10.1111/j.1654-109x.2009. 01036.x

Dürr, C., Dickie, J. B., Yang, X. Y., and Pritchard, H. W. (2015). Ranges of critical temperature and water potential values for the germination of species worldwide: contribution to a seed trait database. Agric. For. Meteorol. 200, 222-232. doi: 10.1016/j.agrformet.2014.09.024

Ellis, R. H., Covell, S., Roberts, E. H., and Summerfield, R. J. (1986). The influence of temperature on seed germination rate in grain legumes II. Intraspecific variation in chickpea (Cicer arietinum L.) at constant temperatures. J. Experi. Bot. 37, 1503-1515. doi: 10.1093/jxb/37.10.1503

Finch-Savage, W. E., and Phelps, K. (1993). Onion (Allium cepa L.) seedling emergence patterns can be explained by the influence of soil temperature and water potential on seed germination. J. Exper. Bot. 44, 407-414. doi: 10.1093/ jxb/44.2.407

Garcia-Huidobro, J., Monteith, J. L., and Squire, G. R. (1982). Time, temperature and germination of pearl millet (Pennisetum typhoides S. \& H.) I. Constant temperature. J. Exper. Bot. 33, 288-296. doi: 10.1093/jxb/33.2.288

González, E., Masip, A., Tabacchi, E., and Poulin, M. (2017). Strategies to restore floodplain vegetation after abandonment of human activities. Restorat. Ecol. 25, 82-91. doi: 10.1111/rec. 12400

Guillemin, J. P., Gardarin, A., Granger, S., Reibel, C., Munier-Jolain, N., and Colbach, N. (2013). Assessing potential germination period of weeds with base temperatures and base water potentials. Weed Res. 53, 76-87. doi: 10.1111/wre. 12000

Gummerson, R. J. (1986). The effect of constant temperatures and osmotic potentials on the germination of sugar beet. J. Exper. Bot. 37, 729-741. doi: 10.1093/jxb/37.6.729

Hardegree, S. P., and Emmerich, W. E. (1990). Partitioning water potential and specific salt effects on seed germination of four grasses. Ann. Bot. 66, 587-595. doi: 10.1093/oxfordjournals.aob.a088068

Hardegree, S. P., and Van Vactor, S. S. (1999). Predicting germination response of four cool-season range grasses to field-variable temperature regimes. Environ. Exper. Bot. 41, 209-217. doi: 10.1016/S0098-8472(99)00 004-0

Harper, J. L., and Harper, J. L. (1977). Population Biology of Plants, Vol. 892 London: Academic press.

Hernández, A. J., and Pastor, J. (2008). "La restauración en sistemas con Suelos degradados: estudio de casos en agroecosistemas mediterráneos y taludes de carretera," in Contaminación de Suelos. Tecnologías Para su Recuperación. Serie Ponencias, eds R. Millán and C. Lobo (Madrid: CIEMAT), 561-580.

Hijmans, R. J., Guarino, L., Bussink, C., Mathur, P., Cruz, M., Barrentes, I., et al. (2004). Diva-Gis. Vsn. 5.0. A geographic information system for the analysis of species distribution data.

Hijmans, R. J., Cameron, S. E., Parra, J. L., Jones, P. G., and Jarvis, A. (2005). Very high resolution interpolated climate surfaces for global land areas. Int. J. Climatol. 25, 1965-1978. doi: 10.1002/joc.1276

Hobbs, R. J., and Norton, D. A. (1996). Towards a conceptual framework for restoration ecology. Restorat. Ecol. 4, 93-110. doi: 10.1111/j.1526-100x.1996. tb00112.x

Kahmen, S., and Poschlod, P. (2008). Effects of grassland management on plant functional trait composition. Agric. Ecosyst. Environ. 128, 137-145. doi: 10. 1016/j.agee.2008.05.016

Kebreab, E., and Murdoch, A. J. (1999). Modelling the effects of water stress and temperature on germination rate of Orobanche aegyptiaca seeds. J. Exper. Bot. 50, 655-664. doi: 10.1093/jxb/50.334.655

Kuiper , J. C., and Bos, M. (eds). (1992). "Ecophysiology of Plantago species. Phenotypic plasticity in Plantago species," in Plantago: A Multidisciplinary Study, Vol. 89 (Heidelberg: Springer). doi: 10.1007/978-3-642-76392-2

Kuiper, P. J., and Bos, M. (eds) (2012). Plantago: A Multidisciplinary Study, Vol. 89 Berlin: Springer Science \& Business Media.

Lawson, C. S., Ford, M. A., and Mitchley, J. (2004). The influence of seed addition and cutting regime on the success of grassland restoration on former arable land. Appl. Veget. Sci. 7, 259-266. doi: 10.1111/j.1654-109x.2004.tb00618.x

Loumou, A., and Giourga, C. (2003). Olive groves: the life and identity of the Mediterranean. Agric. Hum. Values 20, 87-95.

Metzger, M. J. (2018). The environmental stratification of Europe, [dataset]. Univ. Edinb. doi: $10.7488 / \mathrm{ds} / 2356$

Moreno-de Las Heras, M., Merino-Martín, L., and Nicolau, J. M. (2009). Effect of vegetation cover on the hydrology of reclaimed mining soils under mediterranean-continental climate. Catena 77, 39-47. doi: 10.1016/j.catena. 2008.12.005

Myers, N., Mittermeier, R. A., Mittermeier, C. G., Da Fonseca, G. A., and Kent, J. (2000). Biodiversity hotspots for conservation priorities. Nature 403:853. doi: $10.1038 / 35002501$

Pearson, T. R. H., Burslem, D. F. R. P., Mullins, C. E., and Dalling, J. W. (2002). Germination ecology of neotropical pioneers: interacting effects of environmental conditions and seed size. Ecology 83, 2798-2807. doi: 10.1890/ 0012-9658(2002)083[2798:geonpi]2.0.co;2

Proulx, S. R., Promislow, D. E., and Phillips, P. C. (2005). Network thinking in ecology and evolution. Trends Ecol. Evol. 20, 345-353. doi: 10.1016/j.tree.2005. 04.004

R Core Team (2016). R: A Language and Environment for Statistical Computing. Vienna: R Foundation for Statistical Computing. Available online at: https: //www.R-project.org/

Rosbakh, S., and Poschlod, P. (2015). Initial temperature of seed germination as related to species occurrence along a temperature gradient. Funct. Ecol. 29, 5-14. doi: 10.1111/1365-2435.12304 
Ross, M. A., and Harper, J. L. (1972). Occupation of biological space during seedling establishment. J. Ecol. 60, 77-88. doi: 10.2307/2258041

Rühl, J., Pasta, S., and La Mantia, T. (2005). Metodologia per lo studio delle successioni secondarie in ex-coltivi terrazzati: il caso studio di Pantelleria (Canale di Sicilia). Forest @-J. Silviculture For. Ecol. 2, 388-398. doi: 10.3832/ efor0324-0020388

Schat, H. (1981). Seed polymorphism and germination ecology of Plantago coronopus L. Acta Oecol. 2, 367-380.

Schröder, R., and Prasse, R. (2013). Cultivation and hybridization alter the germination behavior of native plants used in revegetation and restoration. Restorat. Ecol. 21, 793-800. doi: 10.1111/rec.12018

Steinmaus, S. J., Prather, T. S., and Holt, J. S. (2000). Estimation of base temperatures for nine weed species. J. Exper. Bot. 51, 275-286. doi: 10.1093/ jexbot/51.343.275

Teixeira, A., Iannetta, P., Binnie, K., Valentine, T. A., and Toorop, P. (2020). Myxospermous seed-mucilage quantity correlates with environmental gradients indicative of water-deficit stress: plantago species as a model. Plant Soil 446, 343-356. doi: 10.1007/s11104-01904335-z

Trudgill, D. L., Honek, A. D. L. I., Li, D., and Straalen, N. M. V. (2005). Thermal time-concepts and utility. Ann. Appl. Biol. 146, 1-14.1.

van Groenendael, J. V. (1986). Life history characteristics of two ecotypes of Plantago lanceolata L. Plant Biol. 35, 71-86. doi: 10.1111/j.1438-8677.1986. tb00463.x van Tienderen, P. H. (1992). Variation in a population of Plantago lanceolata along a topographical gradient. Oikos 64, 560-572. doi: 10.2307/3545176

Welbaum, G. E., Tissaoui, T., and Bradford, K. J. (1990). Water relations of seed development and germination in muskmelon (Cucumis melo L.) III. Sensitivity of germination to water potential and abscisic acid during development. Plant Physiol. 92, 1029-1037. doi: 10.1104/pp.92.4.1029

Windram, O., and Denby, K. J. (2015). Modelling signaling networks underlying plant defence. Curr. Opin. Plant Biol. 27, 165-171. doi: 10.1016/j.pbi.2015.07. 007

Xu, J., Li, W., Zhang, C., Liu, W., and Du, G. (2014). Variation in seed germination of 134 common species on the eastern Tibetan Plateau: phylogenetic, life history and environmental correlates. PLoS One 9:e98601. doi: 10.1371/journal.pone. 0098601

Conflict of Interest: The authors declare that the research was conducted in the absence of any commercial or financial relationships that could be construed as a potential conflict of interest.

Copyright (c) 2020 Teixeira, Toorop and Iannetta. This is an open-access article distributed under the terms of the Creative Commons Attribution License (CC BY). The use, distribution or reproduction in other forums is permitted, provided the original author(s) and the copyright owner(s) are credited and that the original publication in this journal is cited, in accordance with accepted academic practice. No use, distribution or reproduction is permitted which does not comply with these terms. 